\title{
AVALIAÇÃO DA INFECÇÃO EXPERIMENTAL PELO Toxocara canis E Ascaridia galli EM FRANGOS Label Rouge ${ }^{l}$
}

\section{Ellen Monteiro Ribeiro Santos ${ }^{1}$; Aristeu Vieira da Silva ${ }^{2}$; Maiana Mascarenhas $\operatorname{Costa}^{3}$ e Allana Thayla Nogueira dos Santos ${ }^{4}$}

1. Bolsista PIBIC/CNPq, Graduando em Ciências Biológicas, Universidade Estadual de Feira de Santana, e-mail: ellenmonteiro28@hotmail.com

2. Orientador, Grupo de Pesquisa em Zoonoses e Saúde Pública, Departamento de Ciências Biológicas, Universidade Estadual de Feira de Santana, e-mail: aristeuvsilva@uefs.br; bolsista de Produtividade em Pesquisa CNPq

3. Participante do projeto, Departamento de Ciências Biológicas, Universidade Estadual de Feira de Santana, e-mail: maianamcosta@gmail.com

4. Participante do projeto, Departamento de Ciências Biológicas, Universidade Estadual de Feira de Santana, e-mail: allana.thayla@hotmail.com

PALAVRAS-CHAVE: Zoonozes; Aves; Geohelmintos.

\section{INTRODUÇÃO}

A criação de frangos em um sistema semi-intensivo, é responsável por potencializar a sobrevivência de ovos no meio ambiente, favorecendo assim as infecções causadas por geohelmintos, atribuindo as aves um papel de indicadores de contaminação ambiental.(OLIVEIRA,2017) Em boa parte das infecções, as aves são acometidas por nematódeos da família Ascarididae (SILVA et.al, 2016) a exemplo do Toxocara canis e Ascaridia galli.

Caracterizada como uma geozoonose de distribuição mundial, a toxocaríase é ocasionada por um nematódeo do gênero Toxocara spp. (Toxocara canis e Toxocara cati), onde o homem, outros mamíferos e aves atuam como hospedeiros paratênicos, onde o parasito não realiza o ciclo completo (RAPOSO, 2014) A infecção pelo Toxocara spp. ocorre pela ingestão de ovos larvados presentes no solo, água, alimentos e no pêlo de animais infectados, as larvas são liberadas no intestino, fazem migração extra intestinal, mas encistam em diversos órgãos e tecidos, onde podem permanecer viáveis por longos períodos. No ser humano podem alojar-se no fígado, pulmões, cérebro e olho, causando as síndromes características (OVERGAAUW, van KNAPEN, 2013).

Poucos estudos experimentais têm sido realizados, segundo Raposo (2014) infecções experimentais com Toxocara spp. são essenciais para avaliação da influência da infecção no desenvolvimento das aves e do comportamento migratório do parasito, infectividade, recuperação de ovos e larvas, além de auxiliar na compreensão das reações cruzadas com outros ascarídeos, a exemplo do Ascaridia galli. Estudos sobre a contaminação cruzada com outros ascarídeos ainda é recente, von Söhsten et al (2017) afirmam que a resposta humoral e celular entre T. canis e A. galli ainda precisa ser avaliada.

\section{MATERIAL E MÉTODOS OU METODOLOGIA (ou equivalente)}

\footnotetext{
${ }^{11}$ Projeto financiado com recursos CNPq e FAPESB.
} 
As aves utilizadas no experimento foram obtidas de criatório comercial, com um dia de idade, sendo utilizadas um total de 20 aves. As mesmas foram alojadas em gaiolas individuais no Laboratório de Fisiologia e Parasitologia Experimental (LaFiPE), do Departamento de Ciências Biológicas, recebendo desde o primeiro dia de alojamento água e ração comercial para frangos de corte ad libitum. O laboratório possuiu monitoramento de iluminação, sendo os animais mantidos em 12 horas de luz e 12 horas de escuro, e sob temperatura constante de $22 \pm 0,5^{\circ} \mathrm{C}$. Do primeiro ao vigésimo primeiro dia de vida as aves foram mantidas no LaFiPE para aclimatação ao ambiente e ganho de peso para a fase experimental propriamente dita.

Com três semanas de vida das aves foi iniciado um Experimento Aleatorizado Fatorial $2 \mathrm{x} 2$, onde três grupos composto por seis frangos e um grupo composto por sete frangos cada foram inoculados da seguinte forma: um grupo de seis aves inoculado com $500 \mu \mathrm{L}$ de solução salina via oral; um grupo de seis aves inoculado com $500 \mu \mathrm{L}$ de solução salina contendo 1000 ovos de Ascaridia galli (obtidos de fêmeas adultas de $A$. galli recolhidas de aves naturalmente infectadas de propriedades rurais do Distrito de Maria Quitéria); um grupo de seis aves inoculado com $500 \mu \mathrm{L}$ de solução salina contendo 1000 ovos de Ascaridia galli e $1000 \mu \mathrm{L}$ de solução salina contendo 2000 ovos de Toxocara canis; e um grupo de sete aves inoculado com $1000 \mu \mathrm{L}$ de solução salina contendo 2000 ovos de Toxocara canis (obtidos de fêmea adulta de Toxocara canis, cedida pela Profa. Simone de Oliveira). No dia da inoculação as aves foram contidas e além de receberam o inóculo descrito para cada grupo, foi coletado uma amostra de 500 $\mu \mathrm{L}$ de sangue pela punção da veia ulnar. Coletas de sangue foram realizadas semanalmente até o fim do experimento.

Na primeira semana pós-inoculação, foram recolhidas as fezes depositadas por cada uma das aves, diariamente, para os exames coprológicos. Ao final da primeira semana pós-inoculação e então a cada sete dias, foram coletadas amostras de fezes de cada uma das aves.

Aos 30 dias pós-inoculação, as aves foram abatidas por deslocamento crâniocervical e logo após, pesadas individualmente; o trato gastro-instetinal, fígado e baço foram coletados. O fígado e o baço foram separados individualmente, pesados $\mathrm{e}$ congelados para posterior exame molecular. O intestino foi mensurado, aberto e seu conteúdo foi drenado. O conteúdo fecal foi utilizado para realização de exames de detecção de ovos de helmintos pelo método de Willis (SLOSS et al., 1999), sendo estágios parasitários contados em câmara de McMaster e MiniFlotac® (MAURELLI et al, 2014)

A mensuração do trato gastro-intestinal, fígado e baço foram avaliados pelos métodos de Análise de Variância para Experimento Fatorial, seguida de teste de Tukey para comparação das médias. Alguns dados não possuiam distribuição Normal, verificada pelo Teste de Shapiro, e então foram avaliados pelo método de KruskallWallis. As amostras de sangue foram centrifugadas a $1.600 \mathrm{~g}$ por 15 minutos para separação do soro, que logo após o soro foi congelado a $-20^{\circ} \mathrm{C}$ para futuros exames de detecção de anticorpos anti-Toxocara e anti-Ascaridia pelo método de ELISA.

\section{RESULTADOS E/OU DISCUSSÃO (ou Análise e discussão dos resultados)}

Os exames coprológicos realizados diariamente e semanalmente; e o conteúdo intestinal coletado após o abate das aves, ambos analisados pelo método de Willis, apresentaram negatividade para a presença de ovos de ascarídeos, apesar do inoculo conter ovos larvados em abundância (Figuras 1 e 2). Não foram observados a presença 
de helmintos jovens ou adultos no intestino das aves. Um fator que pode estar atrelado aos resultados é o curto período de tempo do experimento, de acordo com von Söhsten et al (2017), o tempo de infeçcão, em estudos experimentais, influencia de forma significativa na recuperação de ovos e larvas.

Figura 1. Microfotografia (aumento de $200 \mathrm{x}$ ) de ovos larvados de Ascaridia galli (a e b) e Toxocara canis (c),Feira de Santana-Ba,2018.
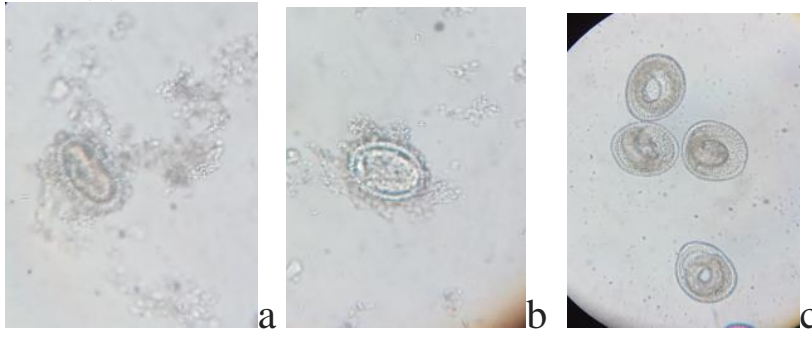

Figura 2. Microfotografia (aumento de 200 x) de um parasito adulto de Ascaridia galli contendo ovos (a e b) e ovos de Toxocara canis(c e d).
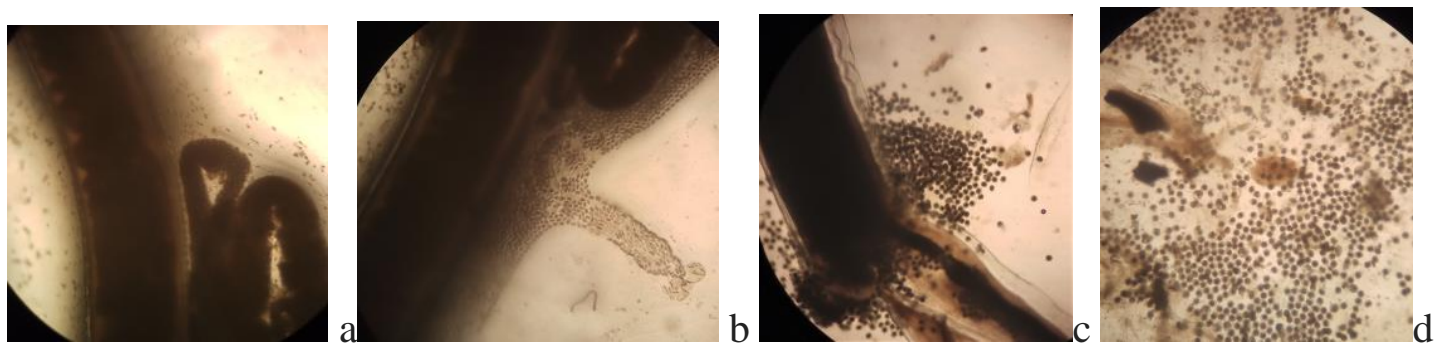

Os dados estatísticos pela ANOVA fatorial (Tabela 2) indicaram interação significativa entre o grupo infectado com Ascaridia galli e a massa corporal das aves. Infecções causadas por Ascaridia galli, em aves são responsáveis pela redução da taxa de crescimento e peso, além de estar atrelada a elevada mortalidade dos frangos (GAULY, HOMANN, e ERHARDT, 2005).

Tabela 1. Massa corporal $(\mathrm{Kg})$ de aves infectadas experimentalmente com Ascaridia galli e Toxocara canis em Feira de Santana-BA,2018

\begin{tabular}{ccccccc}
\hline Variável & $\mathrm{N}$ & Média & $\begin{array}{c}\text { Desvio } \\
\text { Padrão }\end{array}$ & Mediana & P25 & P75 \\
\hline G1 & 5 & $1,76^{\mathrm{b}}$ & 0,21 & 1,70 & 1,67 & 1,73 \\
G2 & 5 & $1,87^{\mathrm{a}}$ & 0,20 & 1,82 & 1,71 & 1,98 \\
G3 & 5 & $2,02^{\mathrm{b}}$ & 0,41 & 2,11 & 1,75 & 2,20 \\
G4 & 5 & $1,60^{\mathrm{b}}$ & 0,19 & 1,68 & 1,52 & 1,70 \\
\hline
\end{tabular}

Observação: valores de médias ou de medianas seguidas de letras minúsculas diferentes indicam diferenças significativas entre os grupos, pelo teste de Tukey; a ANOVA fatorial indicou interação significativa entre Ascaridia galli e a massa coporal; em todos os testes considerou-se um valor de significância de 0,05 .

Tabela 2. ANOVA fatorial da massa corporal $(\mathrm{Kg})$ de aves infectadas experimentalmente com ovos de Ascaridia galli e Toxocara canis em Feira de Santana - BA, 2018.

\begin{tabular}{cccc}
\hline Variável & Ascaridia galli $(\mathrm{G} 2)$ & Toxocara canis $(\mathrm{G} 4)$ & Interação $(\mathrm{G} 3)$ \\
\hline $\mathrm{F}$ & 4,820 & 0,006 & 1,642 \\
Grau de liberdade & 1,16 & 1,16 & 1,16 \\
$\mathrm{p}$ & 0,04 & 0,93 & 0,21 \\
\hline
\end{tabular}


Caracterizado como órgão linfóide secundário, o baço, juntamente com os vasos linfáticos, outros órgãos e tecidos atuam na resposta imune e na mobilização de linfócitos para zonas específicas (QURESHI,2003). Parasitoses são responsáveis por alterar alguns aspectos do órgãos linfóides, como coloração e massa. A estatística (Tabela 3) mostra uma interação significativa entre a massa do baço e Ascaridia galli e a relação entre Ascaridia galli e Toxocara canis.

Tabela 3. ANOVA fatorial da massa (em g) do baço de aves infectadas experimentalmente em Feira de Santana-Ba,2018.

\begin{tabular}{cccc}
\hline Variável & Ascaridia galli $(\mathrm{G} 2)$ & Toxocara canis $(\mathrm{G} 4)$ & Interação $(\mathrm{G} 3)$ \\
\hline $\mathrm{F}$ & 7,173 & 0,361 & 4,672 \\
Grau de liberdade & 1,16 & 1,16 & 1,16 \\
$\mathrm{p}$ & 0,01 & 0,56 & 0,04 \\
\hline
\end{tabular}

Tabela 4. Massa (g) do baço de aves Infectadas experimentalmente com ovos de Ascaridia galli e Toxocara canis em Feira de Santana-BA, 2018.

\begin{tabular}{ccccccc}
\hline Variável & $\mathrm{N}$ & Média & $\begin{array}{c}\text { Desvio } \\
\text { Padrão }\end{array}$ & Mediana & P25 & P75 \\
\hline G1 & 5 & $2,21^{\mathrm{b}}$ & 0,44 & 1,97 & 1,89 & 2,50 \\
G2 & 5 & $2,31^{\mathrm{a}}$ & 0,31 & 2,41 & 2,09 & 2,45 \\
G3 & 5 & $2,83^{\mathrm{a}}$ & 0,65 & 2,56 & 2,45 & 3,51 \\
G4 & 5 & $1,92^{\mathrm{b}}$ & 0,07 & 1,94 & 1,89 & 1,95 \\
\hline
\end{tabular}

Observação: valores de médias seguidas de letras minúsculas diferentes indicam diferenças significativas entre os grupos, pelo teste de Tukey; a ANOVA fatorial indicou interação significativa entre Ascaridia galli e a massa do baço; em todos os testes considerou-se um valor de significância de 0,05 .

O comprimento das alças intestinais (intestino delgado, cecos e intestino grosso), bem como a massa do fígado, mesmo quando corrigidos pela massa corporal, não apresentaram diferenças significativas entre os grupos experimentais (Valor de $\mathrm{P}>$ $0,05)$.

\section{CONSIDERAÇÕES FINAIS (ou Conclusão)}

De acordo com os resultados é possível inferir que o período curto do experimento influenciou diretamente na avaliação da eliminação e reeliminação fecal de ovos de Toxocara canis e Ascaridia galli, pelas aves, sendo mais viável para esse tipo de objetivo a realização do experimento durante no mínimo dois meses,que corresponde ao período pré-patente médio para A. galli. A partir dos dados quantitativos foi possível avaliar a influência das infecções do T. canis e A. galli no desenvolvimento ponderal de frangos, permitindo assim uma maior compreensão acerca dessas infecções e da capacidade das aves como potenciais reservatórios zoonóticos.

\section{REFERÊNCIAS} OLIVEIRA, Adilson Cardoso de. Frequência de Anticorpos Anti-Toxocara em Frangos Criados em Sistema Semi-intensivo, no Norte do Paraná,Sul do Brasil. 2015. 49 f. Dissertação (Mestrado) - Curso
de Ciência Aminal, Universidade do Oeste Paulista, Presidente Prudente-sp, 2017. Disponível em: 〈http://bdtd.unoeste.br:8080/jspui/bitstream/jspui/1063/2/ADILSON OLIVEIRA.pdf>. Acesso em: 28 jul. 2018. SILVA, Gs da et al. Helminthic Parasites of Chickens (Gallus Domesticus) in Different Regions of São Paulo State, Brazil. Revista Brasileira de Ciência Avícola, [s.l], v. 18, n. 1, p.163-168, mar. 2016.
FapUNIFESP (SciELO). http://dx.doi.org/10.1590/18069061-2015-0122. Disponível em: 〈http://www.scielo.br/scielo.php?pid=S1516-635X2016000100163\&script=sci_arttext>. Acesso em: 28 jul. 2018.

RAPOSO, R. S. Infecção experimental de frangos com Toxocara canis: cinética e avidez de anticorpos IgY. 2014. Dissertação (Mestrado em Ciência Animal). Universidade do Oeste Paulista, Presidente Prudente. $46 \mathrm{f}$

OVERGAAUW, P. A, van KNAPEN, F. Veterinary and public health aspects of Toxocara spp. Vet Parasitol, v. 193, n. 4, p. 398-403, 2013

von SÖHSTEN, A. L. et al. Anti-Toxocara spp. IgY antibodies in poultry sold in street markets from Feira de Santana, Bahia, Northeastern Brazil. Veterinary Parasitology: Regional Studies and Reports, v. 8 , n. 1 , p. $86-9,2017$

GAULY, M.; HOMANN, T.; ERHARDT, G.. Age-related differences of Ascaridia galli egg output and worm burden in chickens following a single dose infection. Veterinary Parasitology, [s.l.], v. 128, n. 1-2, p.141-148, mar. 2005. Elsevier BV. http://dx.doi.org/10.1016/j.vetpar.2004.11.023

QURESHI, M. A. Avian macrophage and immune response: An overview, Poultry Science, v. 82, p. 691-698, 2003. 